BNL 845 (T-332)

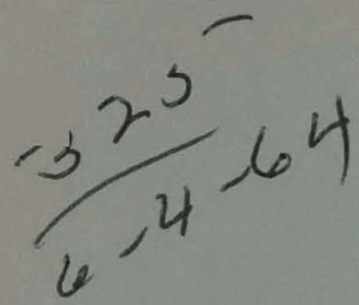

\title{
THE EFFECT OF REACTOR IRRADIATION UPON HYDROGEN ADSORPTION BY AN ALUMINA CATALYST
}

\section{D.B. ROSENBLATT AND G.J. DIENES}

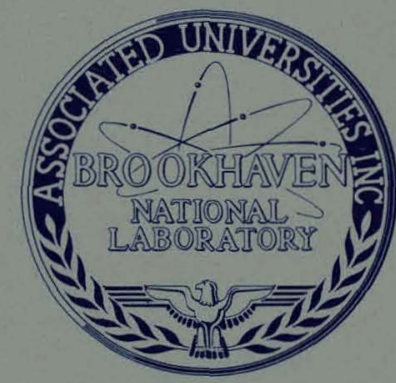

February 1964

BROOKHAVEN NATIONAL LABORATORY ASSOCIATED UNIVERSITIES, INC. under contract with the UNITED STATES ATOMIC ENERGY COMMISSION 


\section{DISCLAIMER}

This report was prepared as an account of work sponsored by an agency of the United States Government. Neither the United States Government nor any agency Thereof, nor any of their employees, makes any warranty, express or implied, or assumes any legal liability or responsibility for the accuracy, completeness, or usefulness of any information, apparatus, product, or process disclosed, or represents that its use would not infringe privately owned rights. Reference herein to any specific commercial product, process, or service by trade name, trademark, manufacturer, or otherwise does not necessarily constitute or imply its endorsement, recommendation, or favoring by the United States Government or any agency thereof. The views and opinions of authors expressed herein do not necessarily state or reflect those of the United States Government or any agency thereof. 


\section{DISCLAIMER}

Portions of this document may be illegible in electronic image products. Images are produced from the best available original document. 


\section{THE EFFECT OF REACTOR IRRADIATION UPON HYDROGEN ADSORPTION BY AN ALUMINA CATALYST

\author{
D.B. Rosenblatt and G.J. Dienes
}

February 1964

BROOKHAVEN NATIONAL LABORATORY UPTON, NEW YORK. 
This report was priepared as an account of Government sponsored work. Neither the United States, nur the Commission, nor any person acting on behalf of the Commission:

A. Mákés àny warranty or representation, expressed or implied, with respect to the accuracy, completeness, or usefulness of the information contained in this report, or that the use of any information, apparatus, method, or process disclosed in this report tuay not infringe privately nwned rights; or

B. Assumes any liabllitles with respect to the use of, or for damages resulting from the use of any information, apparatus, method, or process disclosed in this report.

As used in the above, "person acting on behalf of the Commission" includes any employee or contractor of the. Commission, or employee of such contractor, to the extent that such employee or contractor of the Commission, or employee of such contractor prepares, disseminates, or provides access to, any information pursuant to his employment or contract with the Comurrission, or his employment will such contractor.

PRINTED IN USA

PRICE 50 CENTS

Available from the Office of Technical Services

Department of Commcrce Washington 25, D.C. 


\begin{abstract}
Hydrogen adsorption experiments were carried out on unirradiated and reactor-irradiated samples of gamma alumina $\left(\gamma-\mathrm{Al}_{2} \mathrm{O}_{3}\right)$ in an effort to interpret the known enhancement by radiation of the catalytic activity of this material. The specific surface area of $85 \mathrm{~m}^{2} / \mathrm{g}$ was not changed by irradiation, but the shapes of the hydrogen adsorption isntherms were altered. The observed monolayer capacity for hydrogen indicates that hydrogen atoms are adsorbed (at $78^{\circ} \mathrm{K}$ ) in one-to-one correspondence with the oxygen ions in the alumina surface. Nitrogen contamination, which is not removed by outgassing at $300^{\circ} \mathrm{C}$, has been detected. It is displaced systematically as hydrogen is adsorbed at $78^{\circ} \mathrm{K}$. Reactor irradiation appears to enhance this nitrogen release phenomenon.
\end{abstract}




\section{THE EFFECT OF REACTOR IRRADIATION UPON 'HYDROGEN ADSORPTION BY AN ALUMINA CATALYST}

\section{INTRODUCTION}

The high specific surface area forms of alumina are extensively used in heterogeneous catalysis. Enhancements have been reported in the catalytic activities of this material after exposure to reactor or gamma radiations. These enhancements were for reactions involving hydrogen, i.e., hydrogendeuterium exchange ${ }^{1}$ and ortho-para hydrogen conversion. ${ }^{2}$ This suggests that there is a change in the manner in which hydrogen is adsorbed and desorbed from this material. In some preliminary work $^{3-5}$ the authors found substantial differences in the adsorption of hydrogen on virgin and irradiated gamma alumina. These investigations have been extended and the results are given in this report.

Changes in catalytic and gas-adsorbing properties are to be expccted if the surface of a solid is altered by exposure to radiation. There is a severe limitation on the choice of physical properties useful as indices of radiation damage to a surface. Electrical resistivity, mechanical measurements, or optical absorption, useful in studying bulk effects, are not readily applied to a few atomic planes. Direct observation of surface effects with the field ion microscope of Muller ${ }^{6}$ is possible, but is limited to a few substances. Young ${ }^{7}$ has used adsorption of krypton on alpha alumina to reveal an increase in the number of highly active adsorption sites after exposure of this material to reactor irradiation. Gas adsurption can, therefore, he, used to detect surface damage, although the interpretation of results is usually not simple.

\section{EXPERIMENTAL PROCEDURE.}

The material used in these experiments was Linde Alumina Type B, reported to consist chiefly of gamma alumina particles of about $80 \AA$, although a fcw relatively large ( $3500 \AA$ ) alpha alumina grains are also present. ${ }^{8}$ Electron diffraction results correspond to the gamma structure. ${ }^{9}$ It is known that complex changes occur in gamma alumina if it is exposed to an increasing sequence of temperatures above $300^{\circ} \mathrm{C}$. After such treatment, reduction in surface area (largely due to sintering), crystallographic changes, and loss of some residual water all take place. ${ }^{10}$ Moreover, infrared studies ${ }^{11}$ have shown that $\mathrm{OH}$ groups are bound to the surface and that the details of this binding are sensitive to sample history. It is hardly surprising that observed catalytic activities vary greatly with the particular method used in calcining and otherwise preparing samples. 'To simplify correlation of the present gas adsorption results with the catalytic properties reported by others, temperatures in excess of $300^{\circ} \mathrm{C}$ were avoided during outgassing of samples. The specific surface areas of samples were then found to be constant and great enough to be characteristir of a catalytically active substance.

After evacuation to pressures of $10^{-5} \mathrm{~mm} \mathrm{Hg}$ at room temperature or at $300^{\circ} \mathrm{C}$, the specific surface areas of samples were determined by nitrogen adsorption at $78^{\circ} \mathrm{K}$ by the B.E.T. method of analysis. Hydrogen adsorption isotherms at $78^{\circ} \mathrm{K}$ were obtained by admitting known quantities of the gas into a constant-volume apparatus containing a sample and measuring the pressures after attainment of equilibrium. The ampoules containing the samples were then evacuated, sealed off, and irradiated to doses of $\approx 10^{18}$ neutrons $/ \mathrm{cm}^{2}$-sec at $50^{\circ} \mathrm{C}$ in the Brookhaven Graphite Research Reactor. The seals of the samples were broken under vacuum by means of magnetically operated hammers to facilitate the measurement of adsorption chararteristics on irradiated samples without any intervening exposure to the atmosphere. After again degassing, measurements of nitrogen or hydrogen adsorption were repeated.

\section{EXPERIMENTAL RESULTS}

\section{Effect of Irradiation on Specific Surface Area}

The specific surface area of the gamma alumina ( $\approx 85 \mathrm{~m}^{2} / \mathrm{g}$, using $16.2 \AA^{2}$ as the area of an adsorbed nitrogen molecule at $78^{\circ} \mathrm{K}$ ) was found to be independent of outgassing temperature between room teriperature and $300^{\circ} \mathrm{C}$ and unaltered by 
subsequent exposure in a reactor to $10^{18}$ neutrons $/ \mathrm{cm}^{2}$-sec. The fact that this radiation dose causes no change in specific surface area does not mean that the surface has been unaffected. Changes in the activity of adsorption sites will not affect the values obtained for the surface area, since the B.E.T. method measures the number of nitrogen molecules adsorbed in the first monolayer, regardless of the details of the gas-solid interaction. In the case of the material used here, the high specific area is due to small particle size, and, unless sintering occurs or conversely porosity develops as a result of irradiation, no change in specific surface area is to be expected. Evidently such macroscopic changes did not occur in these samples, although they could certainly take place at higher radiation doses. Young, ${ }^{\top}$ in about the same dose range, found no change in the specifle surface area of alpha alumina.

\section{Effect of Irradlation on Hydrogen Adsorption}

The isotherms obtained for hydrogen adsorption on a particular gamma alumina sample (wt, 1.498 g) before and after irradiation are shown in Figure 1. Irradiation affects not only the amount of adsorption but also the shape of the isotherm. However, the initial portions on both curves may be fitted by the Langmuir relationship $\Theta=k P /(1+$ $k P$ ), where $\Theta$ is coverage, $P$ is pressure, and $k$ is a

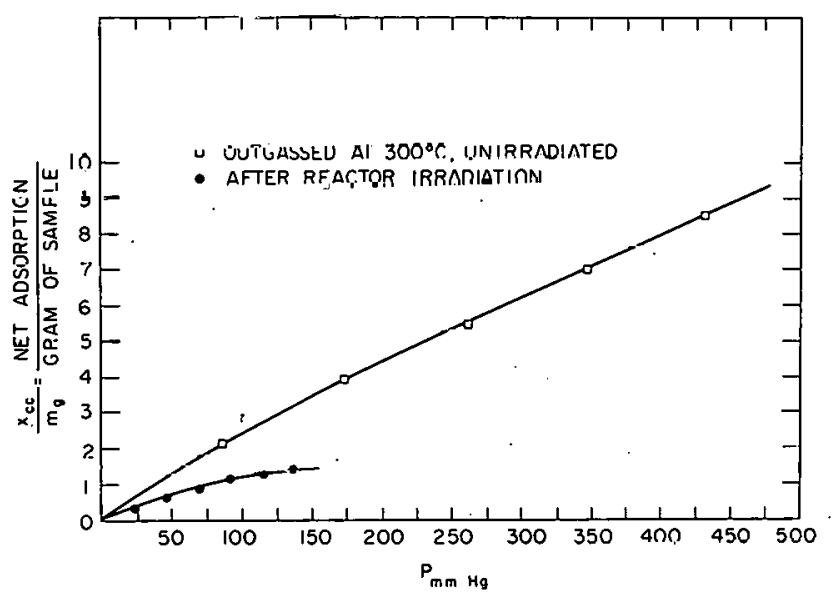

Figure 1. Specific net adsorption of gas vs total pressure for hydrogen admitted to gamma alumina powder at $78^{\circ} \mathrm{K}$. Data are shown for the same sample before and after reactor irradiation to $\approx 10^{18}$ neutrons $/ \mathrm{cm}^{2}-\mathrm{sec}$ at $50^{\circ} \mathrm{C}$. Mass spectrometer a nalysis was carricd out on the gas after the last admission of hydrogen to the irradiated sample (last data point on lower curve). temperature-dependent constant. The data, therefore, could be analyzed as follows. By algebraic rearrangement the Langmuir equation may be put into the linear form

$$
P /(x / m)=1 /(A B)+P / B
$$

where $x$ is the number of molecules adsorbed at equilibrium on a sample of $m$ grams at pressure $P$, $B$ is the number of molecules required to complete a monolayer on $1 \mathrm{~g}$ of sample, and $A$ is proportional to the ratio of the sticking probability to the evaporation rate. If $P /(x / m)$ is plotted vs $P$, the data will fall on a straight line in the Langmuir region and the constants $B$ and $A$ can be calculated from the slope $1 / B$ and the intercept $1 / A B$.

Figure 2 presents several runs for the same samplc as in Figure 1, but replotted in the linear form. The data for the unirradiated sample follow a straight line up to $P \cong 300 \mathrm{~mm} \mathrm{Hg}$, with $B \cong 24$ $\mathrm{cc} / \mathrm{g}$. Aftcr adsurption of $\approx 6 \mathrm{cc} / \mathrm{g}$, there is a drastic change in the manner of packing of hydrogen on the alumina surface, as indicated by the abrupt change in slope. After irradiation the behavior of the sample is entirely different:The initial $B$ value is now between 5 and $6 \mathrm{cc} / \mathrm{g}$, or $\approx 1 / 4$ of the value for the unirradiated case.

Experiments with a large number of samples (see Figure 3) showed that the amounts of hydrogen adsorbed as well as the shapes of the isotherms

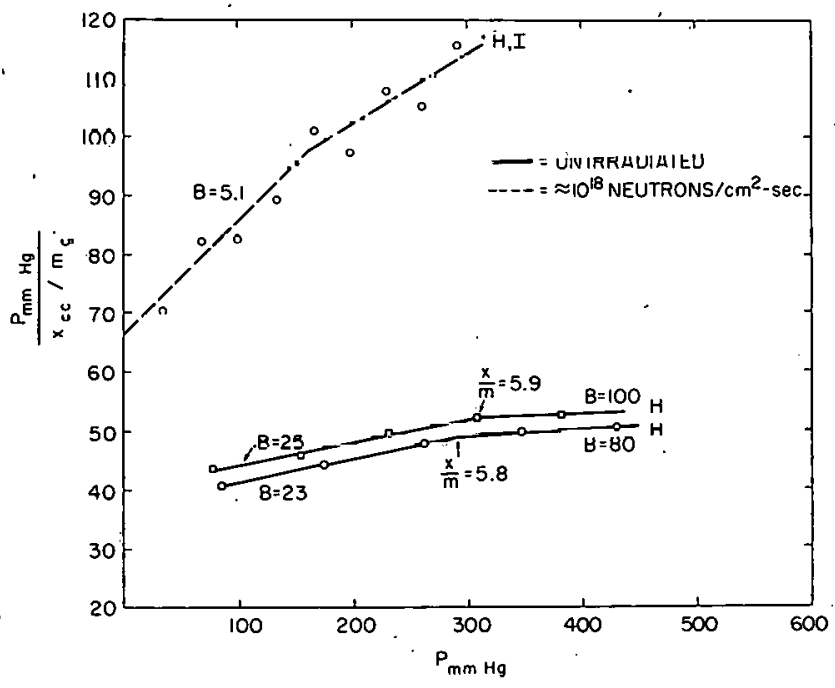

Figure 2. $P /(x / m)$ vs $P$, where $x$ is loss in gas phase, curves for hydrogen adsorption for unirradiated and irradiated alumina. 'I'he initial slope of the lower curves indicates a monolayer capacity of $\approx 24 \mathrm{cc} / \mathrm{g}$ and changes in slope at $\approx x / m=6 \mathrm{cc} / \mathrm{g}$. 
varied greatly from sample to sample. Even though the samples used had been subdivided from the same original lots of powder, variations occurred between the unirradiated samples. There were also differences in behavior between various irradiated samples. However, the results are not random; the isotherms indicate that two different modes of adsorption are prevalent, with adsorption on the irradiated samples being characterized by only one of these modes. In Figure 3 two different unirradiated samples (the solid lines) are shown; each sample was run twice, and the curves for a single sample lie adjacent to one another. Data for several irradiated samples are also shown (the dashed curves). These curves all lie above those obtained for the unirradiated samples. Examination of curves such as those of Figure 3 reveals that, in general, the results may be divided into the following three cases: unirradiated type 1, with initial $B \cong 24 \mathrm{cc} / \mathrm{g}$; unirradiated type 2 , with initial $B \cong 6$ $\mathrm{cc} / \mathrm{g}$; and irradiated samples for which initial $B$ also $\simeq 6 \mathrm{r.r} / \mathrm{g}$.

The isotherms of Figure 4 may be compared with the linear plots of Figure 3. The changes in slope of Figure 3 correspond to the changes in curvature of Figure 4. Type 1 adsorption is represented by the points falling along the solid line in Figure 4. As is explained later, this probably results from adsorption on a relatively clean sample,

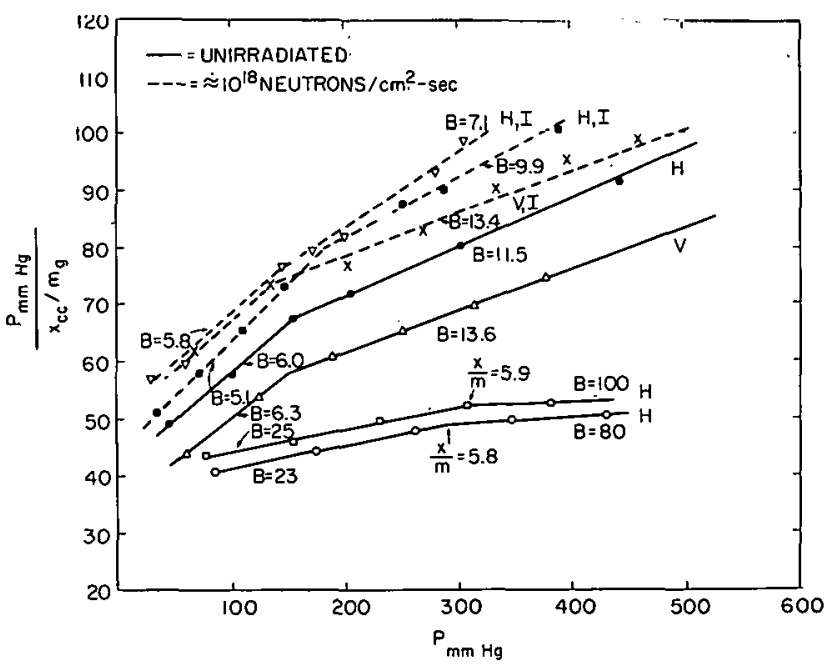

Figure 3. Plots of $P /(x / m)$ vs $P$ for unirradiated and reactor-irradiated samples. The two lowest curves represcnt data for a "clean" sample. The labels $H, V$, and $I$ refer to outgassing at $300^{\circ} \mathrm{C}$, outgassing at room temperature, and irradiation to $\approx 10^{18}$ neutrons $/ \mathrm{cm}^{2}$-sec, respectively. whereas the other data are influenced by nitrogen contamination. Some of this nitrogen is driven into the gas phase when hydrogen is adsorbed, which results in a lowering in the net gas adsorption; i.e., the observations, which consist of measurements of loss of molecules from the gas phase, are reduced when nitrogen is evolved. The runs in Figure 4 that do not follow the solid curve belong to type 2 adsorption, in which adsorbed hydrogen replaces nitrogen and a reduction in the net adsorption results.

\section{Mass Spectrometer Evidence for Nitrogen Contamination}

In Figure 4 the lowest curve, marked M.S., shows unusually small net adsorption, and therefore substantial nitrogen release was suspected in this case. Consequently, the gas involved in this run was subjected to mass spectrometer analysis. After the last admission of hydrogen $\left(\right.$ at $\left.78^{\circ} \mathrm{K}\right)$ to the dead volume containing the sample (the last point shown for sample 100-I in Figure 4) the gas was analyzed and found to consist of $88 \%$ hydrogen and $12 \%$ nitrogen. Since only hydrogen was ad-

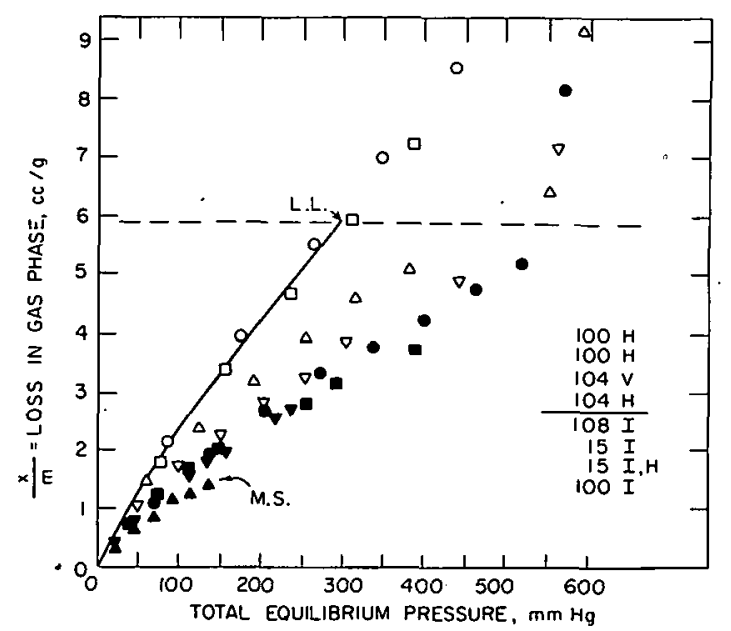

Figure 4. Specific adsorption vs total pressure for various alumina samples. The solid line through the open circles and squares indicates that part of the data (unirradiated "clean" sample) that follows Langmuir adsorption with a monolayer capacity of $24 \mathrm{cc} / \mathrm{g}$. Open points are for unirradiated samples, filled points are for samples preirradiated to $\approx 10^{1 s}$ neutrons $/ \mathrm{cm}^{2}$-sec. Sample numbers and treatment are indicated: $H=$ heating to $300^{\circ} \mathrm{C}$ during preliminary outgassing; $V=$ degassed at room temperature; $I=$ reactor irradiated, $I, H=$ reactor irradiated followed by degassing at $300^{\circ} \mathrm{C}$. The limit for Langmuir adsorption is indicated by L.L. 
mitted, the nitrogen must have been displaced from the sample as the hydrogen was adsorbed. The difference between the known quantity of hydrogen admitted and that remaining in the gas phase as shown by the mass spectrometer, i.e., the true hydrogen adsorption, was $4.42 \mathrm{cc} / \mathrm{g}$ of sample. The gaseous nitrogen (by the mass spectrometer result) was $3.02 \mathrm{cc} / \mathrm{g}$. The net observed adsorption should therefore be $4.42-3.02=1.40 \mathrm{cc} / \mathrm{g}$, which is close to the observed net adsorption of $1.39 \mathrm{cc} / \mathrm{g}$.

\section{Chemical Analysis of Linde Alumina Type B}

Spectroscopic analysis cited by the manufacturer indicated that the material was relatively free from ordinary impurities, but no estimate of nitrogen content was furnished. Quantitative chemical analysis of a number of fresh samples yielded very variable results, with a typical nitrogen content of 200 $\mathrm{ppm}$. This amount of nitrogen, even if fully released, would not account for the sizable effect observed directly in the mass spectrometer experiment. However, surface nitrogen contamination would probably not show up in the chemical analysis. A simple calculation shows that a monolayer of nitrogen corresponds to $24,000 \mathrm{ppm}$ of nitrogen for the particle size of these samples.

\section{DISCUSSION}

It is well known that very high tcmperatures and advanced vacuum techniques are required to free the surfaces of metallic oxides from all traces of original gas. Moreover, gamma alumina possesses surface water which changes to bound hydroxyl groups in a complicated fashion as the temperature is increased. " Any effort to get a "pure" surface would result in a material totally different from those used in catalysis. The character of the surfaces after degassing at room temperature or $300^{\circ} \mathrm{C}$ for $24 \mathrm{hr}$ at $10^{-5} \mathrm{~mm} \mathrm{Hg}$ must be regarded as unknown and not necessarily reproducible. The radiation-induced enhancements in the catalytic activity of gamma alumina demonstrated by others and referred to here in the introduction are apparently not due to an increase in surface area, which remains constant at $85 \mathrm{~m}^{2} / \mathrm{g}$.

In our experiments we have found (from the initial slopes of type 1 adsorption isotherms of Figure 2 and Figure 3 ) that $24 \mathrm{cc} / \mathrm{g}$ of hydrogen would complete a monolayer, or, if the measured surface area is used, the area occupied by a hydrogen molecule is

$$
\frac{24}{85 \times 10^{20}} \frac{\mathrm{cc}}{\AA^{2}}=13.2 \AA^{2} \text { per molecule of } \mathrm{H}_{2} \text {. }
$$

This result is in approximate agreement with the experiments of de Boer et al. ${ }^{12}$ on the chemisorption of water in alumina. These workers showed that water molecules occupy $12.1 \AA^{2}$ per molecule of water. They claim that the most probable lattice plane in the surface will be the (111) plane of the spinel lattice, in which each oxygen ion takes in $6.74 \AA^{2}$ of surface. Consequently each water molecule in the experiments of de Boer et al. is chemisorbed to two oxygen ions in the alumina surface. In the hydrogen case, our experiments indicate that adsorption at low pressures occurs on all available sites and these hydrogen atoms are chemisurbed in assuciation with one oxygen surface ion. At higher pressures, when the coverage is about $6 \mathrm{cc} / \mathrm{g}$, the nature of the adsorption changes. Ar these pressures more hydrogen is adsorbed than indicated by the simple Langmuir isotherm valid at low pressures.

The remaining curves of Figure 3 probably reflect contamination with nitrogen. This is suggested by the mass spectrometer analysis of the gas which is in contact with the powder.

From the data of Figure 4, the differences between the solid line (type 1 adsorption) and the rest of the data are approximately linear with respect to pressure. This observation is difficult to interpret, but one may speculate as follows. Let the hydrogen displace nitrogen from the sample at a constant rate. The released nitrogen will be partly readsorbed on the surface by physical ad. sorption. The rate of gaseous nitrogen production and destruction may be written as

$$
\begin{gathered}
\frac{d \mathrm{~N}_{2}{ }^{g}}{d t}=K_{1} \mathrm{H}_{2}{ }^{0}+K_{2} \mathrm{~N}_{2}{ }^{s}, \\
-\frac{d \mathrm{~N}_{2}{ }^{g}}{d t}=K_{3} \mathrm{~N}_{2}{ }^{g},
\end{gathered}
$$

where

$\mathrm{N}_{2}{ }^{0}=$ concentration of nitrogen in gas phase,

$\mathrm{N}_{2}{ }^{8}=$ concentration of nitrogen on solid,

$\mathrm{H}_{2}{ }^{\circ}=$ concentration of hydrogen in gas phase.

Under steady state conditions

$$
\mathrm{N}_{2}{ }^{0}=\left(K_{1} / K_{3}\right) \mathrm{II}_{2}{ }^{0}+\left(K_{2} / K_{3}\right) \mathrm{N}_{2}{ }^{s} \text {. }
$$

At luw nitrogen pressures the nitrogen adsorption isotherm is approximatcly lincar, giving

$$
\mathrm{N}_{2}{ }^{s}=K_{4} \mathrm{~N}_{2}{ }^{p} \text {, }
$$


and therefore

$$
\left(1-\frac{K_{2} K_{4}}{K_{3}}\right) \mathrm{N}_{2}{ }^{0}=\frac{K_{1}}{K_{3}} \mathrm{H}_{2}{ }^{g} \quad \text { or } \quad \mathrm{N}_{2}{ }^{0}=K \mathrm{H}_{2}{ }^{0} .
$$

Thus, this speculation suggests that the major difference between type 1 and type 2 behavior is that in the latter case nitrogen is released. This release of nitrogen is facilitated by prior irradiation of the samples. The unirradiated type 2 samples appear to correspond to various degrees of nitrogen contamination.

The existence of an original layer of adsorbed nitrogen may be of significance for a qualitative understanding of the catalytic properties of gamma alumina. It is known that the unirradiated material has a variable catalytic behavior depending upon the heating and outgassing procedures used. Kohn and Taylor ${ }^{1}$ report that the choice of degassing technique affects the subsequent radiation enhancement of the material's catalytic activity. Maurin, Ballantine, and Sucher ${ }^{2}$ obtained no increase in catalytic activity when they irradiated in vacuum, but did obtain an increase when hydrogen was in contact with the alumina during irradiation. This result appears to be in accord with the conclusions reached here, i.e., irradiation in vacuum does not remove the nitrogen contamination but nitrogen is replaceable by hydrogen.

\section{ACKNOWLEDGMENTS}

The experimental procedures were devised by W.L. Kosiba and R.C. Weed, who also carried out some of the surface area measurements. Some of the hydrogen adsorption measurements were made by J.C. Rothmann. The authors are indebted to D.A. Young for many suggestions concerning both the experimental and theoretical aspects of this problem. Thanks are due to L. Friedman and A.P. Irsa for the mass spectrometer measurements, to H.L. Finston for the chemical analyses of samples, and to J. Jach and T.B. Flanagan for helpful discussions.

\section{REFERENCES}

1. H.W, Kohn and E.H. TAYlor, J. Phys. Chem. 63,500 (1959).

2. J. Maurin, D.S. Ballantine, and J. Sucher, Unpublished work, BNL, 1958.

3. D.B. Rosenblatt, G. J. Dienes, and J.C. Rothmann, Bull. Am. Phys. Soc. 5, 167 (1960).

4. G. J. Dienes, in International Conference on Chemical Reactivity of Solids, Amsterdam, May 30 -June 4, 1960, p. 416, Elsevier, Amsterdam, 1961.

5. D.B. Rosenblatt and G. J. Dienes, Bull. Am. Phys. Soc. 8, 363 (1963).

6. E.W. Muller, J. Appl. Phys. 28, 1 (1957).

7. D.A. Young, J. Phys. Chem. Solids 15, 119 (1960).

8. R.G. Rudness, The Linde Company, Private communication.

9. H.W. KoHN, Private communication.

10. A.S. Russell et Al., Alcoa Research Laboratories Technical Paper No. 10 (Revised), pp. 25-39, Aluminum Company of America, 1956.

11. J.B. Peri and R.B. Hannan, J. Phys. Chem. 64, 1526 (1960).

12. J.H. DE Boer et AL., J. Catalysis 2, 1 (1963). 